\title{
Editorial: Poverty, Vulnerability and Resilience in a Post-2015 World
}

\author{
Laura Camfield • Andrew Crabtree $\cdot$ Keetie Roelen
}

Accepted: 16 November 2012/Published online: 16 March 2013

(C) Springer Science+Business Media Dordrecht 2013

\section{Introduction}

Current statistical data suggest that there is mixed progress towards achieving the Millennium Development Goals (MDGs) by 2015. Some MDGs such as access to safe drinking water have already been reached at the global level (WHO/UNICEF 2012). However, such global success is largely due to overachievements by a few large developing countries such as China (UN 2012). In other countries progress is limited and this is especially so in Sub-Saharan Africa (Easterly 2009) and fragile and conflict affected states (UN 2012). Looking ahead, the global economic crisis (2007) may mark the end of a relatively benign era of strong growth, buoyant aid budgets and reasonable stability. Poverty reduction will then need to be pursued in a context of economic recovery, climate change, urbanization and demographic change.

The MDGs can be considered successful in stimulating action at the international level and in many nations. Discussions about what should replace the MDGs post-2015 are in full swing. Should there be a new framework? If so, what should it include? What global process would produce it? How would local ownership of development processes fit with universal goals set by the United Nations? This special issue tackles key questions within international development policy and practice around the achievements, strengths and weaknesses of the MDGs. It also explores the kinds of policies, targets, and institutions that can support resilience and innovation in an increasingly uncertain world, and how alternative thinking and understandings of poverty can be incorporated in the MDGs post-2015. Finally, the issue looks at the global processes of deliberation needed to build political momentum, and the relationships between climate change and other shocks, poverty, and

L. Camfield (更)

Department of International Development, University of East Anglia,

Norwich Research Park, Norwich, Norfolk NR4 7TJ, UK

e-mail: L.Camfield@uea.ac.uk

\author{
A. Crabtree \\ Copenhagen Business School, Copenhagen, Denmark
}

K. Roelen

Institute for Development Studies, Brighton, UK 
psychosocial wellbeing. The papers mix theory and practice and support their conclusions with analyses of international data sets and examples from Bihar, Ethiopia, South Africa, Thailand, and Bangladesh. They were presented as part of a panel run by the joint European Association of Development Research and Training Institutes (EADI)-Development Studies Association (DSA) working group on Multi-dimensional Poverty and Poverty Dynamics at the EADI-DSA International Conference in 2011.

The timing of this special issue is opportune as it captures a transitional moment between the MDGs and whatever will replace them. This process involves review, consultation, debate and planning on a global scale. It will culminate in a UN event in September 2013 to lay the foundations for consensus on the post-2015 UN development agenda, informed by the recommendations of an expert panel in spring 2013.

There is a contrast between the preparations for the first set of MDGs over 10 years of UN summits from 1990 onwards and the two year slot (2013-2015) allocated to their replacement after 2015. This difference may exemplify what Hulme and Wilkinson (2012:10-11) describe as a shift from the "age of voice" that preceded the MDGs to a post-MDG "age of measurement" by technical elites. While grassroots representation in the setting of the original goals was said to be dominated by northern Non-Governmental Organisations (NGOs) rather than southern civil society organisations, Hulme and Wilkinson (2012) argue that now the voices of the poor are mediated by researchers and 'experts'. They suggest that this leads to a lack of sensitivity to contexts and the particular problems of different groups of the poor, causing international institutions to "see" policy subjects in the same ways and construct problems that are seen as resolvable via one-size-fits-all policies. The authors in this special issue draw similar conclusions, favouring MDGs that are built from the national level or even from the bottom up, and informed by holistic, people-centred, sustainable and politically sensitive frameworks such as human security or wellbeing.

\section{Overview of Papers}

The special issue has two different but linked sections; the papers in the first section largely review lessons from the MDGs and imagine their future post-2015, and the papers in the second section consider and discuss concerns and emerging issues that the MDGs post2015 will need to engage with in an increasingly volatile world.

The first paper by Unterhalter and Dorward reviews the strengths and weaknesses of the MDGs across a range of sectors, particularly education and health. The paper argues that efforts at the top and bottom in implementing the MDGs have been disconnected. They discuss five principles, namely (i) Holism, (ii) Equity, (iii) Sustainability, (iv) Ownership, and v) Global obligation and how they can guide both 'top-down' or 'bottom-up' processes in post-2015 MDG formulation and implementation. The second paper by Guillen-Royo, Velazco and Camfield explores factors affecting individual goal satisfaction in Bangladesh and Thailand to address the broader question of whether the common practice of classifying goals as 'universal' (e.g. health) or 'local' (e.g. community relationships) has any empirical support. The authors argue on the basis of their results from a regression analysis that both types of goals should be given equal priority and need to be taken into account to better understand people's wellbeing and assess progress in development. Finally, Lo Bue and Klasen take an empirical look at differential performance in achieving MDGs. They use cluster analysis to divide countries into three groups-good performers, low performers and partial performers - and explore how particular political, institutional and geographic factors can increase the likelihood of belonging to a given cluster. While their 
aim was to find synergies in goal achievement, they found that more often success in one goal was traded off against failure in another.

The second section, on concerns and issues to be taken into account in post-2015 discussions, opens with a paper by Sumner and Mallet looking at how increasing instability as a result of the interaction of population size and structure, climate change, and food and energy prices requires a realignment of our theoretical lenses. They propose a 'three-dimensional human wellbeing' approach as an alternative to conventional understandings of poverty and discuss its potential for integrated analyses of household vulnerability and as the theoretical and ethical basis for the MDGs post-2015. Maclay and Marsden take a similar theoretical perspective in their analysis of extremely poor households in Bangladesh participating in a conditional cash transfer scheme (CCT). Maclay and Marsden maintain that demand-driven CCTs - programmes that offer cash grants on request - enable poor people to satisfy their immediate needs and make them more likely to invest in future-oriented activities such as children's schooling. Without this support they claim that poor people will be unable to change their behaviour due to the psychosocial impact of extreme poverty. Crabtree's article also highlights the importance of looking at issues of psychosocial impact in evaluating the adequacy of MDG7's call for the integration of sustainable development into country policies and the development of Sustainable Development Goals (SDGs) following Rio +20 . It argues for the importance of including mental health in a possible Disaster Risk Reduction MDG and SDG as mental health problems following extreme weather events are widespread. Based on fieldwork carried out after the 2008 Kosi River flooding and the existing epidemiological literature, Crabtree questions George Bonanno's claim that following Potentially Traumatic Events (PTEs) the vast majority of people are resilient, defined as a trajectory of a "relatively stable, healthy levels of psychological and physiological functioning" (Bonanno 2004:20). Rather he claims that the vast majority of people have sub-clinical symptoms of disorders. Instead of seeing a flood as one PTE, he emphasizes the importance of examining the multiplicity of psychosocial stressors that have different consequences and require different responses, including profound socio-cultural changes. Finally, Camfield and Roelen look at trade-offs between the wellbeing of children and their households as households move in and out of poverty. They draw on qualitative and quantitative data from Young Lives, a longitudinal study of children growing up in poverty, which covers a period of rapid economic growth in rural Ethiopia (2002-9). The paper concludes that while there is considerable 'churning', there is always a core of extremely poor households (approximately $13 \%$ ) whose welfare presents the greatest challenge to the MDGs post-2015. Nonetheless, the outcomes for children in these households in relation to education, work and leisure may in some cases be better than those for children in wealthier households.

In the remainder of the editorial we briefly review the successes and failures of the MDG framework and outline some of the options for its replacement and the timescale within which this will take place.

\section{MDGs Then and Now}

Although the Millennium Declaration was made on the 8th September 2000, the MDG agenda only took off in 2002 when leaders from developed countries pledged to commit $0.7 \%$ of $\mathrm{GNP}^{1}$ on financing development at the Monterrey conference (McArthur 2012).

1 By 2011 only five countries had reached this target and on average members of DAC were contributing $0.3 \%$, http://webnet.oecd.org/oda2011/. 
The impetus that this promise of resources gave to the goals, even if the resources did not always materialise - is important to bear in mind for discussions of the MDGs post-2015 given shrinking aid budgets. The MDGs were initially perceived as 'top-down'-they were originally intended as targets not for developing country governments, but for the OECD's Development Assistance Committee in disbursing overseas aid-but were later seen as a tool for citizens to hold their governments to account (ibid). At first the MDGs had little traction with the World Bank or global business and philanthropy. However, they increased in popularity in the mid-2000s, as evidenced by the World Bank's current claim that "these goals are our goals" 2 and their praise by the North American philanthropist Bill Gates in a speech to the UN in 2008.

Despite countries renewing their commitment to meet MDG targets at a UN Summit in 2008 , it seems likely that many of the goals will not be met or that the quality of the work to meet these goals may not be adequate (McGregor and Sumner 2010). For example, decline in extreme poverty (MDG1), as well as improvements in other MDGs, has been concentrated in China (UN 2012). While rates of poverty in Sub-Saharan Africa improved, the absolute number of poor people did not due to population increase. There are also large disparities in outcomes within countries by gender, location, and socio-economic status, as we discuss later. The anticipated failure to meet MDG targets can be partially attributed to the recent global crises - the percentage of GNP given as overseas aid by the OECD fell for the first time in 2011 since 1997 and falls were particularly evident in countries such as Greece $(39 \%)$ and Spain $(33 \%)$ which have been affected by the Eurozone crisis. ${ }^{3}$

The decline in financial stability of some OECD economies may reflect a new era where the division between developed and developing countries is blurring as "substantial groups in rich and high middle-income countries experience absolute poverty in some important aspects of life, including employment, income security, and psychological and social aspects and even larger numbers have a major risk of joining those groups for at least some period" (Koehler et al. 2012:11). ${ }^{4} \mathrm{New}$ challenges for any replacement to the MDGs include volatile world food and energy prices, climate change (there has been a fivefold increase in natural disasters since the 1970s, mainly affecting developing countries (UN 2012)) and energy and water shortages. There is also the challenge of reducing greenhouse gas emissions while enhancing access to energy, shortfalls in global food production, rising obesity and other non-communicable diseases, and a double burden of over and under nutrition in some developing countries. Unemployment and underemployment ${ }^{5}$ are global problems and only $28 \%$ of the global population are covered by comprehensive social protection (UN 2012). There are inequalities in access to Information Communications Technology (ICT) and more basic services, growing youth unemployment (increasing migration and threatening social cohesion) and increases in population. These trends are combined with ageing populations, even in developing countries, few of whom will have access to pensions. There are now one billion migrants, a quarter of whom are international, which sharpens the interest of those in the Global North in tackling poverty in the Global South. There is also increasing urbanisation-70\% of the world's population will

\footnotetext{
2 http://www.worldbank.org/mdgs/, downloaded 14/10/12.

3 http://www.oecd.org/newsroom/developmentaidtodevelopingcountriesfallsbecauseofglobalrecession.htm, Downloaded 14/10/12.

4 See also Kanbur and Sumner (2011), who observe that the majority of the poor are now in middle income countries.

5 Koehler et al. (2012) observe that recent growth has been 'jobless' with increasing precaricity of employment and a failure to address inequality and poverty.
} 
live in cities by 2050 - and an estimated $33 \%$ of urban residents in developing countries live in slums (UN 2008).

This evidence of increasing insecurity and volatility caused the 2010 MDG Review Summit to highlight the need for state-funded social protection schemes and a Social Protection Floor to address poverty and vulnerability-what the International Labour Organisation (ILO) describe as

A basic set of essential social rights and transfers, in cash and in kind, to provide a minimum income and livelihood security for all, as well as the supply of an essential level of goods and social services such as health, water and sanitation, education, food, housing, life and asset-saving information that are accessible for all.

ILO, 2011 in Koehler et al. (2012:8)

The broader remit for development proposed by the ILO is echoed in the conceptual frameworks discussed in the papers in this special issue: three-dimensional human wellbeing (Sumner and Mallet), longitudinal poverty (Camfield and Roelen), and sustainability (Crabtree). These frameworks reflect a shift from measuring income to wellbeing (e.g. the Sarkozy commission, Stiglitz et al. 2009) and a greater emphasis on relational aspects of poverty such as social exclusion, which were not captured by the MDGs. The frameworks underpin new attempts at a Millennium Declaration (e.g. Karver et al. 2012) that acknowledges the importance of "strong networks of social protection", "civil and political rights", reduction in military expenditure, and a clear role for developed countries where "high-income countries share responsibilities towards global development that extend considerably beyond development assistance" (ibid:36). However, the proposed revisions also acknowledge that the original Millennium Declaration, and even the MDGs themselves, had some strengths, which we discuss in the following section.

Finally, it has to be noted that re-envisioning of development and the responsibilities of countries in the global North is taking place alongside the rise of new development actors and funding opportunities. These include BRICS countries such as Brazil and India. These new economic and political powers have developed distinctive approaches to poverty reduction and alleviation in the areas of public works employment, social protection, access to food and nutrition and the right to information. McArthur (2012:19) observes "a realignment of economic influencers and institutions [where] dividing lines between developed and developing nations have blurred". In addition, there are new funding options, e.g. enlarged tax revenue in developing countries, new philanthropies, and the encouragement of deficit spending rather than austerity by the International Monetary Fund (IMF) to avoid global recession. Business and civil society, including universities, are playing an increasing role in development, and citizens are becoming more active through the growth in mobile technology. According to McArthur (2012) mobile phone subscriptions have risen from 700 million in 2000 to roughly six billion today, many of which provide access to the internet.

\section{MDG Strengths}

As we consider how to meet these challenges and the potential role of the actors described above, it seems timely to return to the MDG framework and consider what worked well. The format of concrete, narrowly focused and time-bound goals, targets and indicators can be seen as a major strength of the MDGs. The reason for this is that it implies a clear framework of accountability, which helped rally popular support. For example, McArthur 
(2012:19) sees the value of the MDGs as their "ambition, simplicity, measurability, and partnership focus". While it is difficult to calculate their impact, it seems likely that they increased aid ${ }^{6}$ and public awareness in richer countries and improved the coordination of aid between donor agencies. They also shifted the focus of aid to lower income countries, especially Sub-Saharan Africa, and changed the language of aid (according to Kenny and Sumner 2011, the MDGs were more frequently talked about than their predecessor goals GDP and the Human Development Index (HDI)). Finally, they improved the data available on multi-dimensional poverty at national and international levels, and provided an early example of results-based development. There is some evidence that aid was focused on goals areas and on smaller countries (who were more likely to meet their targets), which suggests that they were affecting the way aid was used as well as the amount of aid that was provided (Kenny and Sumner 2011).

Hulme and Wilkinson (2012:4) conclude that "on balance, the MDGs have contributed to improvements in human welfare through direct (increased and somewhat more effective foreign aid) and indirect means (contributing to the evolution of an international social norm that finds extreme poverty in an affluent world morally unacceptable)". Nonetheless, as Kenny and Sumner (2011:21) observe "it is a considerable step from "more rapid progress' to 'the MDGs caused more rapid progress"'.

\section{MDG Weaknesses}

The MDGs have been criticised for a number of different reasons. Firstly, they have contributed to misrepresentation of the role of foreign aid in poverty reduction (Peet 2009: 169), for example, by increasing public Afro-pessimism with corresponding effects on investment in Africa (Easterly 2009) and World Bank and IMF influence over public finance and plans in aid-dependent countries. Representing the MDGs as a destination rather than a means may have created a "policy space for development practice to continue with 'business as usual'" (McGregor and Sumner 2010:107) (for example, failing to look at development in relation to, e.g. trade and migration policy). This tendency may have been exacerbated by the lack of a coherent conceptual framework for the MDGs, including a 'theory of change', which would have outlined how the anticipated changes were expected to take place (e.g. how extreme poverty can be reduced). Another reason for slow progress in achieving the MDGs may have been insufficient discussion of the policy processes that would be required for this. Koehler et al. (2012) argue that you need to give countries space to adopt heterodox macro and sectoral policies, e.g. to improve quality of employment, and bolder policies in areas such as land reform, rural poverty and reduction of malnutrition.

A second critique of the MDGs relates to something that is also seen as their strength, namely, their focus on a small number of goals. ${ }^{7}$ This focus came at the price of failing to capture the breadth of the UN Millennium Declaration. It entailed the omission of areas such as productive employment, violence against women, social protection, inequalities, social exclusion, biodiversity, persistent malnutrition and increase in non-communicable diseases, demographic change, peace and security, governance, law and order, and human rights. The

\footnotetext{
${ }^{6}$ Overseas development aid climbed from $\$ 72$ to $\$ 128$ billion between 2000 and 2009, reversing a global downturn (Kenny and Sumner 2011).

${ }^{7}$ Critics have also observed that there were overlapping goals in education and three goals in health (Karver et al. 2012).
} 
goals also failed to reflect subjective definitions of poverty and wellbeing, although these are incorporated in some of the national MDGs. For example, in the World Bank-funded 'Consultations with the Poor' study (Narayan et al. 2000), poor people identify risk, vulnerability, security, dignity and voice, as well as jobs and infrastructure as important elements of poverty. The MDGs may have taken too narrow a focus on the goals they selected, for example, targeting education rather than learning, and equality in access to education rather than gender equality. They also focused on inputs rather than outputs, for example, assuming that universal primary education would ensure literacy. The MDGs were also weak on equity, rights, vulnerability and exclusion-related issues (Karver et al. 2012), and did not pick up differences in achievement within countries, e.g. by gender or location. For example, Kenny and Sumner (2011) contrast a national average of $42 \%$ of underweight children in South Asia with $56 \%$ of underweight children in the poorest income quintile.

Thirdly, the MDGs failed to account for different contexts and country-specific starting points. This includes vulnerability to natural hazards and other external shocks-according to UN (2012:18) "no low-income country affected by violence or fragility has achieved a single MDG target". Also, the targets were not appropriate for Sub-Saharan Africa-in fact, Easterly (2009:29) argued that for some countries they would require progress at faster rates than any historical trajectory ever recorded-which led to perceptions of failure despite improvements. This problem arose from the lack of differentiation between global goals, e.g. for a two-thirds reduction in child mortality worldwide, and country-specific goals. A two-thirds reduction in child mortality is not necessarily attainable for every country and if every country were to meet an MDG of two-thirds reduction, then the average global reduction would be considerably higher than two-thirds. It was difficult to predict performance for different countries in different goal areas, e.g. due to volatility of income growth, and as a result some targets were too conservative. For example, historical trend data suggests that MDG1 was likely to be met at the global level anyway due to growth in countries such as India and China who account for more than a third of the global population. Pogge (2010) suggests that the MDGs were made less ambitious by choosing a 1990 baseline for performance and by using percentages rather than the absolute number of disadvantaged people (the Millennium Declaration mentions reducing numbers). This was necessary due to the 'tightrope' walked by MDG architects "between ambitious targets set at UN conferences and practical targets that could plausibly be met and were politically palatable, all on the basis of weak and missing data" (ibid:18). Measures of on-track/offtrack for country performance were also crude since it would be more useful to know in assessing the value of the MDGs whether countries have had faster or slower progress rates on indicators since their adoption.

Fourthly, although MDG7 (ensuring environmental sustainability) called for the full integration of sustainability, discussions around the emerging Sustainable Development Goals (SDGs) show its weaknesses. The relationship between MDGs and SDGs is unclear, but the Outcome Document of Rio +20 The Future We Want asserted that they should "compliment and strengthen" (para. 108) the MDGs. The exact list is, like the MDGs post2015 , work in progress, but these are likely to include climate change, forestry and biodiversity, land degradation and desertification, mountains, chemicals and wastes, sustainable consumption and production, education and gender issues. Clearly there are overlaps, and possible synergies with MDGs, but there are also potential conflicts, for example the management of the oceans and immediate livelihood loss. The UN Taskforce see the adoption of a human security framework as potentially more progressive than adopting the SDGs as even though these span economic, social and environmental dimensions, they omit human rights (UN 2012). 
Finally, goals were not seen as binding on industrialised countries, even MDG8 on global cooperation. The commitments of developed countries were vague and often not fulfilled and this was especially in relation to access to predictable development finance, export markets, technologies and medicines.

\section{New Ideas and Lessons for the Future}

Hulme and Wilkinson (2012:3) remark dryly that "recasting the world's biggest promise"freeing the entire human race from want" — in a new and improved form... will not be an easy task". Nonetheless, there are areas where improvements can be made, as discussed in the earlier sections of this editorial.

Firstly, a new framework or set of goals needs to address inequality and promote national and local ownership. It needs to distinguish between content and process and ensure that the process by which the goals are selected is seen as legitimate and promotes accountability. This can be achieved through greater transparency in debates and negotiations, reducing dominance of International Financial Institutions (IFIs) such as the World Bank and the IMF, etc., and possibly even including direct citizen participation.

In addition to inequality reduction and deepening national ownership, key elements for the MDGs post-2015 (Karver et al. 2012) are better reporting, monitoring and accountability, including for donors and IFIs. The MDGs needs to be not only about improving the conditions of the poor, but also about reshaping global governance. The anticipated failure to meet MDG targets means that human development and poverty reduction are still important. As we discussed in relation to Goal 8, the MDGs post-2015 should therefore be seen as global development goals and not 'marginal development goals' (as they have sometimes been dubbed), especially as failures in the South bring risks and costs for the North. One way to do this would be through greater specification of MDG8 ("develop a global partnership for development") as Hulme and Wilkinson (2012:11) note that "[highincome] countries insisted... on detailed targets and dates for everything except the changes for which they were responsible" (for example, access to drugs, debt, climate change, trade, etc.).

Finally, the MDGs post-2015 need to address means as well as ends, for example, the fit between macroeconomic policies and development objectives. This includes retaining the flexibility to tailor targets to regional, national and sub-national conditions and priorities, while respecting international standards. It also pertains to extending the framework to take a more inclusive and dynamic perspective.

So how can this long wish-list be accomplished? The UN task force review (UN 2012) proposes that any new framework should be centred around core values of human rights, equality and sustainability. They recommend maintaining the MDG focus on concrete goals and targets-although this is by no means a foregone conclusion, e.g. see the discussion in Kenny and Sumner (2011)_but taking a more holistic approach in four dimensions. These dimensions are felt to more accurately reflect the MDG declaration: (1) inclusive social development; (2) inclusive economic development; (3) environmental sustainability; and (4) peace and security. The return to the Millennium Declaration would involve extending and reframing some aspects of it, for example, ensuring that progress was rights-based and participatory, prioritising economic and social equity and environmental sustainability, jobs and decent work, and moving away from a North-South dichotomy. The UN Taskforce argues that this can be done through a human security framework that addresses complex risks and vulnerabilities at all levels from a social 
justice perspective (see also Koehler et al. 2012). The reason for this is that human security provides an intellectual frame concerning interconnectedness and human vulnerability with values centred on basic human rights (freedom from want, indignity, fear and violence), established agendas for action to build the capacity to avoid, respond to or cope with risks and threats, and an existing presence in many UN agencies, NGOs and universities (including UN General Assembly discussions in 2008 and 2010).

The papers in this special issue also allow for the identification of guiding principles for the formulation of MDGs post-2015. Firstly, context-specificity and bottom-up involvement emerge as crucial issues to be embedded in any set of indicators or framework that is to follow the MDGs. The contributions by Unterhalter and Dorward, Guillen-Royo, Velazco and Camfield, Crabtree and Lo Bue and Klasen all point towards the need to better account for and reflect local needs, goals and context to lessen the disconnect between top-down coordination of efforts and improvement of the lives of those affected. Secondly, coverage of current and emerging challenges at global and more local levels appears as another key aspect of the MDGs post-2015. Unterhalter and Dorward argue that the MDGs largely reflect sectoral concerns and thereby fail to incorporate broader issues of freedom, tolerance, solidarity and responsibility despite the inclusion of these issues in the Millennium Declaration. Crabtree emphasises the importance of including a goal related to disaster risk reduction. Increased volatility and vulnerability due to climate, economic and social crises are concerns that are flagged by Sumner and Mallet. Thirdly, the need for a dynamic and multidimensional perspective arises as another key component of the MDGs post-2015. Camfield and Roelen illustrate how longitudinal analyses of poverty, rather than investigations at a single point in time, from a multidimensional perspective can give insight into the complex interplay of factors over the life course. Similarly, the three-dimensional wellbeing framework proposed by Sumner and Mallet highlights the importance of considering outcomes beyond the material, such as effects on social, relational and psychosocial spaces. In their contributions, Maclay and Marsden and Crabtree explicitly consider the benefits of looking at impacts at the psychosocial level.

All these proposals present challenges of measurability and political sensitivity. There are no internationally agreed measures of the quality of a country's governance or respect for rights, for example. New targets also require good historical data, but this militates against extending goals to include more subjective and relational aspects. There may also be a fine balance between a limited set of universal goals and recognising that national targets may need to differ from this, dependent on the needs of the context. Monitoring data would need to be disaggregated to ensure the needs of the most deprived and vulnerable groups are being addressed, and the ability of people to hold their institutions to account could be increased through benchmarks and better measures of progress, disseminated through independent media, ICT and social media. Finally, we need humility about the extent to which global agreements can change things. As discussed in the contribution of Sumner and Mallet, we need a more humble view of development as providing enabling environments rather than providing wellbeing.

\section{References}

Bonanno, G. A. (2004). Loss, trauma, and human resilience: Have we underestimated the human capacity to thrive after extremely aversive events? American Psychologist, 59(1), 20-28.

Easterly, W. (2009). How the Millennium development goals are unfair to Africa. World Development, $37(1), 26-35$. 
Hulme, D., \& Wilkinson, R. (2012). Brave new world: Global development goals after 2015. BWPI working paper 168 .

Kanbur, R., \& Sumner, A. (2011). Poor countries or poor people? Development assistance and the new geography of global poverty. CEPR discussion paper 8489.

Karver, J., Kenny, C., \& Sumner, A. (2012). MDGs 2.0: What goals, targets and timeframe? IDS working paper 398.

Kenny, C., Sumner, A. (2011). More money or more development: What have the MDGs achieved? Center for Global Development working paper 278.

Koehler, G., Gasper, D., Jolly, R., \& Simane, M. (2012). Human security and the next generation of comprehensive human development goals. IDS working paper, Hague, Netherlands.

McArthur, J. (2012). Rethinking global development goals. Stanford Social Innovation Review.

McGregor, J. A., \& Sumner, A. (2010). Beyond business as usual: What might 3-D wellbeing contribute to MDG momentum. IDS Bulletin, 41(1):104-12.

Narayan, D., Chambers, R., Shah, M., \& Petesch, P. (2000). Voices of the poor: crying out for change. Oxford: Oxford University Press for the World Bank.

Peet, R. (2009). Unholy trinity: The IMF, World Bank and WTO, second edition. London: Zed Books.

Pogge, T. (2010). Millions killed by clever dilution of our promise. Polity. CROP poverty brief. August 2010.

UN Task Team on Post-2015 (2012). Realizing the future we want for all: report to the secretary-general. http://www.beyond2015.org/sites/default/files/Realizing\%20the\%20future\%20we\%20want.pdf,down loaded14/1012.

Stiglitz, J., Sen, A., \& Fitoussi J.-P. (2009). Report by the commission on the measurement of economic performance and social progress. http://www.stiglitz-sen-fitoussi.fr/documents/rapport_anglais.pdf.

United Nations Human Settlements Programme (UN-Habitat), State of the World's Cities 2010/2011: Bridging the Urban Divide (Nairobi, 2008).

WHO/UNICEF Joint Monitoring Programme for Water Supply and Sanitation (2012). Progress on drinking water and sanitation 2012. 